\title{
Enriquecimento protéico da palma forrageira com Saccharomyces cerevisiae para alimentação de ruminantes
}

\author{
[Protein enrichment of cactus pear with Saccharomyces cerevisiae for ruminants feeding] \\ L.F. Araújo ${ }^{1}$, F.L.H. Silva ${ }^{2 *}$, E.A. Brito ${ }^{1}$, S. Oliveira Júnior ${ }^{1}$, E.S. Santos ${ }^{1}$ \\ ${ }^{1}$ Empresa Estadual de Pesquisa Agropecuária da Paraíba - João Pessoa, PB \\ ${ }^{2}$ Universidade Federal de Campina Grande \\ Rua Aprígio Veloso, 882 \\ 58102-012 - Campina Grande, PB
}

\begin{abstract}
RESUMO
Avaliou-se o processo de enriquecimento protéico da palma forrageira (Opuntia ficus-indica Mill) com levedura Sacharomyces cerevisiae em cultivo semi-sólido, visando melhorar o valor nutritivo da palma para ser utilizada na alimentação de ruminantes. A levedura foi utilizada nas concentrações de 1,2 e $3 \%$ em base úmida no substrato formado pela palma forrageira, incubada em biorreatores durante $6,12,24$ e 36 horas de fermentação. O delineamento experimental foi inteiramente ao acaso, em arranjo de parcelas subdivididas com quatro repetições. O conteúdo de proteína bruta quando se utilizou concentração de $3 \%$ de inóculo, no período de seis horas, aumentou de 4,4\% na forma in natura para 10,4\% após o processamento. Os teores protéicos na concentração de $1 \%$ do inóculo foram de $6,1,8,1,8,1$ e $9,2 \%$; na concentração de $2 \%, 9,6,9,7,9,8$ e $9,8 \%$ e na concentração de $3 \%, 10,4,10,4$ 7,9 e 7,9\%, nos períodos de $6,12,24$ e 36 horas de fermentação, respectivamente. Uma fonte alternativa para arraçoamento de ruminantes, pode ser obtida pela bioconversão da palma forrageira.
\end{abstract}

Palavras-chave: palma forrageira, Opuntia ficus-indica Mill, cultivo semi-sólido, proteína bruta

\begin{abstract}
The process of protein enrichment of the forage palm (Opuntia ficus-indica Mill) using the Saccharomyces cerevisiae yeast in a semi-solid culture to improve the nutritional value of forage palm for ruminants feeding was evaluated. The yeast concentrations of 1,2 and $3 \%$ (wet basis) in the forage palm substrate were used. The periods of incubation were of 6,12, 24, and 36 hours. A complete randomized experimental design in a split plot arrangement with four replicates was used. The crude protein content increased from $4.4 \%$ (in natura) to $10.4 \%$ when $3 \%$ of inoculums were used and the processing period was of 6 hours. The observed protein contents for $1 \%$ of the inoculum, used for the fermentation periods of $6,12,24$, and 36 hours were 6.1, 8.1, 8.1, and $9.2 \%$, respectively. These values were 9.6, 9.7, 9.8, and 9.8\% for $2 \%$ of the inoculum, and 10.4, 10.4, 7.9, and $7.9 \%$ for $3 \%$ of the inoculum, respectively. An alternative for ruminant feeding can be obtained by bioconversion of forage palm.
\end{abstract}

Keywords: forage palm, Opuntia ficus-indica Mill, semi-solid culture, crude protein

\section{INTRODUÇÃO}

Apesar da importância socioeconômica da pecuária no semi-árido do Nordeste brasileiro, os sistemas produtivos de exploração animal apresentam baixos índices de produtividade, em função de vários fatores, principalmente escassez de alimentos. Nessa região, os animais estão sujeitos a problemas

Recebido em 31 de maio de 2007

Aceito em 14 de fevereiro de 2008

*Autor para correspondência (corresponding author)

E-mail: flhs@deq.ufcg.edu.br alimentares por causa do longo período de estiagem, quando a pastagem nativa, sua principal fonte forrageira, apresenta baixa produtividade, diminuta capacidade de suporte e baixo valor nutritivo, que restringem a produção de carne e leite (Araújo, 2004).

A vegetação predominante é a caatinga hiperxerófila, que se apresenta normalmente 
densa, com porte arbóreo e, com menos freqüência, arbóreo-arbustiva. Devido à ação antrópica, essa vegetação encontra-se muito devastada, sendo a utilização agrícola da região bastante intensa, com culturas de subsistência. As espécies mais encontradas são: catingueira (Caesalpinia pyramidalis), umbuzeiro (Spondias tuberosa), baraúna (Schinopsis brasiliensis), juazeiro (Zizyphus joazeiro), marmeleiro (Cróton sonderianus), facheiro (Cereus squamosus) e mandacaru (Cereus jamacaru).

$\mathrm{Na}$ tentativa de superar tais problemas, os criadores recorrem ao uso de concentrados comerciais para suplementação protéica na dieta dos animais, o que onera substancialmente os custos de produção, tornando a atividade antieconômica. Os freqüentes aumentos dos preços da suplementação protéica, utilizada na dieta dos animais, têm estimulado o interesse pelo aproveitamento de alimentos não convencionais na indústria de alimentação animal do Brasil. Dentre os produtos que podem substituir os suplementos protéicos, destacam-se os microrganismos, algas, fungos filamentosos e leveduras, considerados fonte unicelular de elevado teor protéico, além de apresentarem rápido crescimento e possibilidade de cultivo em vários tipos de substratos (Butolo, 2001).

Durante a Segunda Guerra Mundial, época em que tornaram escassos os alimentos ricos em proteínas e vitaminas, os alemães produziram, em certa escala, leveduras e o fungo Geotrichum candidum para serem usados na alimentação humana, conforme citaram Frazier e Westhoff, 1993.

As leveduras, presentes na nutrição humana e animal, destacam-se entre os organismos processadores de proteínas, pela alta eficiência na conversão, sendo reconhecidas como fonte protéica e reserva natural de vitaminas do complexo B, com valor nutritivo, em termos de digestibilidade e valor biológico, em torno de $87 \%$, relativamente alto quando comparados ao valor biológico do ovo de galinha, na ordem de 96\% (Peppler, 1970).

Dos vegetais disponíveis na região para serem utilizados como substratos e que apresentam características favoráveis ao desenvolvimento desses microrganismos, destaca-se a palma forrageira. Essa cactácea é uma das mais promissoras do semi-árido, por fornecer alimento aos animais durante o período de estiagem. Esse alimento aumenta a disponibilidade de forragem e alivia o problema do suprimento hídrico aos animais. Embora possua características adaptáveis às condições adversas da região, apresenta limitações em relação ao teor de proteínas e vitaminas. Com o cultivo de microrganismos, esse vegetal pode aumentar seu valor nutricional ao ser acrescido de proteína microbiana, fósforo, potássio e vitaminas do complexo B, importantes fatores de crescimento para os animais (Vilas Boas e Esposito, 2000).

Os substratos abundantes e de baixo custo comumente utilizados no Brasil para enriquecimento protéico são: resíduos de banana, maça, caju, abacaxi, farinhas, espiga de milho, cana-de-açúcar, bagaço de cana, melaço, vinhaça, farelo de palha de trigo, grão-de-bico, polpa de café, arroz cozido, casca de limão, laranja, rejeito de fabricação de polpa congelada de acerola, maracujá, goiaba e morango; castanha de caju. Citam-se também as cactáceas mandacaru sem espinhos e palma forrageira. Todos representam, no Brasil, matéria-prima abundante de baixo custo (Holanda et al., 1998; Vilas Boas e Espósito, 2000; Campos et al., 2005, Araújo et al., 2005; Correia et al., 2007; Pimentel et al., 2007).

Este trabalho teve como objetivo avaliar o efeito do enriquecimento protéico da palma forrageira com a levedura Saccharomyces cerevisiae, visando melhorar sua composição químicobromatológica para ser utilizada na alimentação de ruminantes na região semi-árida.

\section{MATERIAL E MÉTODOS}

O trabalho foi realizado na Estação Experimental de Pendência em Soledade, PB, localizada na Mesorregião do Agreste Paraibano, na Microrregião do Curimataú Ocidental, no período de novembro de 2004 a fevereiro de 2005.

O clima, segundo a classificação de Köppen (1936), é do tipo BSh (semi- árido quente). Essa faixa semi-árida entre o leste e o oeste paraibano é a área mais seca do Estado, com precipitações anuais baixas e uma estação seca que pode atingir 11 meses. A média de temperatura máxima anual é de $34,5^{\circ} \mathrm{C}$ e a mínima de $16,5^{\circ} \mathrm{C}$. 
A umidade relativa do ar é, em média, de $50 \%$, e a precipitação pluviométrica de $400 \mathrm{~mm}$ anuais, concentrada nos meses de abril e maio.

O substrato usado para o enriquecimento protéico foi a palma forrageira (Opuntia ficusindica Mill) variedade gigante, e o microrganismo utilizado para o processo de bioconversão da palma forrageira foi a levedura Saccharomyces cerevisiae, prensada, do tipo comercial fermento biológico fresco, com umidade de $80 \%$ (base úmida) e teor médio de proteína bruta de $45 \%$ (base seca).

Os cladódios da palma forrageira foram extraídos nas articulações, utilizando apenas aquelas em bom estado fitossanitário, a partir das terciárias, conforme a colheita realizada tradicionalmente na região. Após o corte, o material foi transportado para um galpão coberto onde as palmas foram trituradas em máquina forrageira, resultando em uma massa com aspecto de mucilagem e de consistência pastosa, constituindo o substrato. Para cada $10 \mathrm{~kg}$ de substrato foi adicionada a concentração de 1,2 ou $3 \%$ de levedura, em base úmida, as quais foram colocadas em baldes de plástico medindo $104 \mathrm{~cm}$ de diâmetro e $50 \mathrm{~cm}$ de altura. Após a inoculação, os substratos foram acondicionados em temperatura ambiente nesses biorreatores devidamente identificados para cada período de fermentação, 6, 12, 24, e 36 horas. Amostras do substrato coletadas e colocadas em recipientes de plásticos hermeticamente fechados e identificados foram armazenadas em freezer a temperaturas de -10 a $-15^{\circ} \mathrm{C}$. Posteriormente, foram colocadas em caixa de isopor e encaminhadas ao laboratório de nutrição para realização de análises da composição químicobromatológica.

Para determinação da matéria seca, fez-se a présecagem do material a $65 \%$, por 72 horas, em estufa de ventilação forçada, de acordo com a técnica descrita pela AOAC (Official..., 1990), para análise da composição química bromatológica, segundo Silva (1998), e da energia bruta, conforme AOAC (Official..., 1990).

O experimento foi realizado em delineamento inteiramente ao acaso, com arranjo de parcelas subdivididas com quatro repetições. As parcelas principais foram representadas pela concentração de leveduras, e as subparcelas pelo tempo de inoculação. Os dados foram submetidos à análise de variância, e as médias por concentração do inóculo foram comparadas pelo teste Tukey a 5\% de probabilidade. A comparação por tempo de inoculação nas concentrações do inóculo foi realizada por análise de regressão. Todas as análises estatísticas foram realizadas com auxílio do programa SAS (User`s..., 1990).

\section{RESULTADOS E DISCUSSÃO}

Os resultados da composição químicobromatológica da palma forrageira na forma in natura foram: matéria seca (MS) 8,0\%; proteína bruta (PB) 4,4\%; matéria mineral (MM) 4,4; matéria orgânica (MO) $85,6 \%$; fibra em detergente neutro (FDN) 46,8\%; fibra em detergente ácido (FDA) 25,6\% e energia bruta (EB) $3315 \mathrm{kcal} / \mathrm{g}$ para servir de referência em relação aos teores da composição química da palma forrageira enriquecida com levedura.

Houve efeito da concentração de levedura $(\mathrm{P}<0,01)$ sobre os teores de $\mathrm{PB}\left(\mathrm{F}=21,28^{* *}\right)$, FDN $\left(\mathrm{F}=8,10^{* *}\right)$ e FDA $\left(\mathrm{F}=18,33^{* *}\right)$ e do o tempo de inoculação $(\mathrm{P}<0,01)$ apenas sobre $\mathrm{o}$ teor de energia bruta $\left(\mathrm{F}=3,45^{* *}\right)$. Houve interação significativa $(\mathrm{P}<0,01) \quad$ entre concentração do inóculo e tempo de inoculação sobre os teores de $\mathrm{PB}\left(\mathrm{F}=10,14^{* *}\right)$ e FDN $(\mathrm{F}=3,90 * *)$.

Na Tab. 1 são apresentadas as porcentagens de PB da palma forrageira, após o processo fermentativo, em quatro períodos, utilizando a levedura Saccharomyces cerevisiae. $\mathrm{Na}$ concentração de $1 \%$ de inóculo, conseguiu-se um aumento da resposta a partir de seis horas de fermentação, atingindo o valor máximo do teor protéico, $9,2 \%$, às 36 horas de incubação. $\mathrm{Na}$ concentração do inóculo de $2 \%$, não houve modificação significativa $(\mathrm{P}>0,05)$ nos teores de PB durante o período de 36 horas de fermentação (cultivo) semi-sólida, e na concentração de $3 \%$ obteve-se o valor máximo para o teor de PB com 6 e 12 horas. Após esse tempo, o teor de PB diminuiu significativamente $(\mathrm{P}<0,05)$, provavelmente devido à sua desnaturação. Os valores de PB encontrados com o enriquecimento nutricional da palma forrageira foram mais elevados que o teor protéico mínimo de 8\% recomendado pelo NRC (Nutrient..., 1996), para manter os microrganismos do rúmen animal. A 
incubação teve efeito rápido, devido à levedura dobrar o teor de proteína bruta no tempo médio de seis horas em sistemas de cultivo semi-sólido, o que está de acordo com Worgan (1973) e Santos et al. (1992).

Na concentração de $1 \%$, o teor de PB aumentou linearmente em função do tempo de inoculação (Fig. 1), à razão de, aproximadamente, $0,08477 \%$ para cada incremento unitário no tempo de inoculação. $\mathrm{Na}$ concentração de $3 \%$, o teor de $\mathrm{PB}$ diminuiu à medida que se aumentou o tempo de inoculação, da ordem de 0,09918\% para cada aumento unitário no tempo de inoculação. Este resultado é em função de a palma forrageira apresentar alto teor de carboidratos solúveis, que são utilizados pela levedura para a síntese de proteína.

Tabela 1. Teores médios de proteína bruta da palma forrageira enriquecida com a levedura Saccharomyces cerevisiae de acordo com a concentração do inóculo e o tempo de inoculação

\begin{tabular}{cccc}
\hline \multirow{2}{*}{$\begin{array}{c}\text { Tempo de inoculação } \\
\text { (horas) }\end{array}$} & \multicolumn{3}{c}{ Concentração do inóculo (\%) } \\
\cline { 2 - 4 } & 1 & 2 & 3 \\
\hline 6 & $6,13 \mathrm{~b}$ & $9,61 \mathrm{a}$ & $10,42 \mathrm{a}$ \\
12 & $8,12 \mathrm{a}$ & $9,69 \mathrm{a}$ & $10,42 \mathrm{a}$ \\
24 & $8,12 \mathrm{a}$ & $9,85 \mathrm{a}$ & $7,92 \mathrm{~b}$ \\
36 & $9,22 \mathrm{a}$ & $9,84 \mathrm{a}$ & $7,91 \mathrm{~b}$ \\
\hline
\end{tabular}

Médias seguidas por letras distintas na coluna diferem entre si pelo teste Tukey $(\mathrm{P}<0,05)$.

Coeficiente de variação $=9,2 \%$

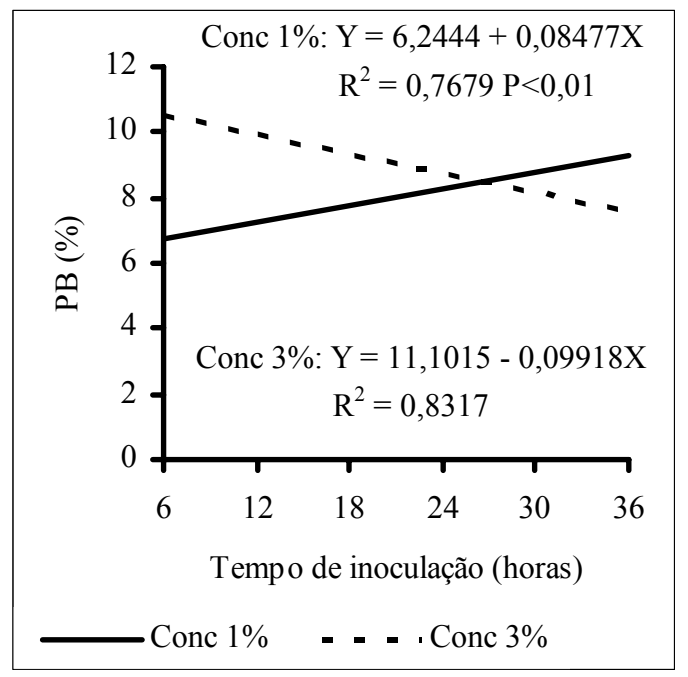

Figura 1. Teor de proteína bruta (PB) da palma forrageira enriquecida com a levedura Saccharomyces cerevisiae, de acordo com o tempo de inoculação e a concentração do inóculo.

Perazzo Neto (1999), ao utilizar Aspergillus niger + uréia no enriquecimento protéico da palma forrageira, encontrou valor de $21,4 \%$ de proteína bruta; Carvalho (1999), na mesma cactácea, ao empregar o Aspergillus níger + Fusarium + uréia, obteve $24 \%$ de PB e Araújo (2004), ao utilizar $15 \%$ da levedura Saccharomyces cerevisiae, obteve 26\% de PB.

O percentual de PB da palma forrageira foi mais alto no tempo de inoculação de 36 horas, nas concentrações de 1 e $2 \%$. Esses valores indicam que o bioproduto atende às exigências mínimas para mantença de pequenos ruminantes, de acordo com o NRC (Nutrient..., 1996), que estabelece 8$10 \%$ de PB. A diminuição ocorrida na concentração de $3 \%$ pode ser atribuída a uma provável volatilização do nitrogênio, produção de amônia e desnaturação gradativa da proteína celular do microrganismo.

A palma forrageira enriquecida com levedura alcançou teores protéicos similares aos do sorgo em grãos $(10 \%)$ e milho em grãos $(9 \%)$, cereais que são bastante utilizados na ração animal.

$\mathrm{Na}$ Tab. 2, apresenta-se a percentagem de FDN da palma forrageira, após o processo fermentativo. $\mathrm{O}$ efeito da concentração do inóculo e o do tempo de fermentação foram significativos sobre os teores de FDN $(53,2 \%)$. Os valores encontrados para os teores deste nutriente no bioproduto estão de acordo com a recomendação do NRC (Nutrient..., 1996) que estabelece no mínimo de $28 \%$ para alimentação de ruminantes.

Observando-se a Fig. 2, na concentração 1\%, o teor de FDN aumentou de forma quadrática $(\mathrm{P}<0,01)$ em função do tempo de inoculação, atingindo valor máximo estimado $(58,32 \%)$ na concentração de inóculo de 19 horas. Por outro lado, na concentração de 3\%, o teor de FDN diminuiu de forma quadrática $(\mathrm{P}<0,05)$, em função do tempo de inoculação, atingindo ponto de mínima estimado $(45,77 \%)$ no tempo de inoculação de 22 horas. 
Enriquecimento protéico da palma...

Tabela 2. Teores médios de fibra em detergente neutro da palma forrageira enriquecida com levedura Saccharomyces cerevisiae para o efeito da interação concentração do inóculo e tempo de fermentação

\begin{tabular}{cccc}
\hline \multirow{2}{*}{$\begin{array}{c}\text { Tempo de inoculação } \\
\text { (horas) }\end{array}$} & \multicolumn{3}{c}{ Concentração do inóculo (\%) } \\
\cline { 2 - 4 } & 1 & 2 & 3 \\
\hline 6 & $51,45 \mathrm{~b}$ & $50,68 \mathrm{a}$ & $50,81 \mathrm{ab}$ \\
12 & $56,38 \mathrm{a}$ & $52,00 \mathrm{a}$ & $47,64 \mathrm{ab}$ \\
24 & $57,38 \mathrm{a}$ & $52,00 \mathrm{a}$ & $45,90 \mathrm{~b}$ \\
36 & $47,51 \mathrm{~b}$ & $52,03 \mathrm{a}$ & $49,52 \mathrm{ab}$ \\
\hline
\end{tabular}

Médias seguidas por letras distintas na mesma linha diferem entre si, pelo teste Tukey $(\mathrm{P}<0,05)$. Coeficiente de variação $=6,67 \%$

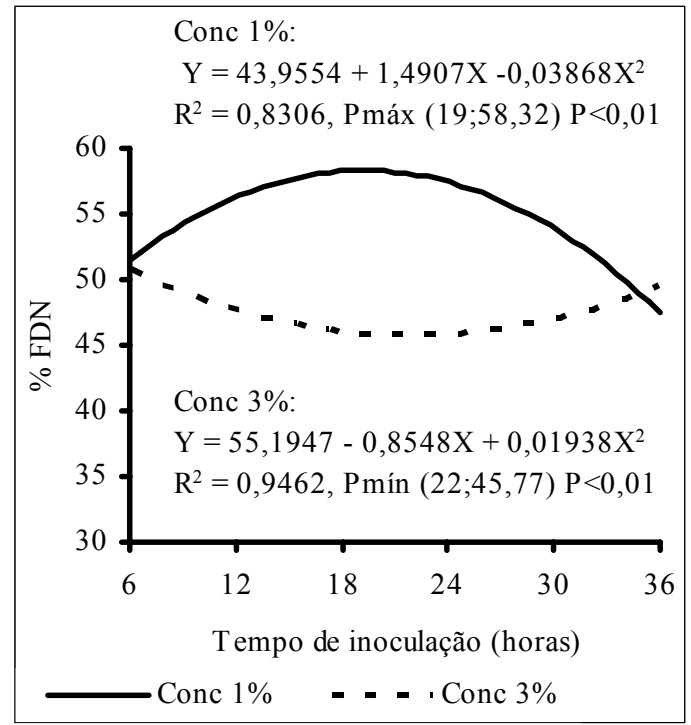

Figura 2. Efeito do tempo de inoculação no teor de fibra em detergente neutro (FDN), nas concentrações do inóculo $1 \%$ e $3 \%$.

$\mathrm{Na}$ concentração $2 \%$, não houve efeito significativo no tempo de inoculação no teor de FDN, mesmo assim os teores de FDN encontrados no bioproduto estão de acordo com as recomendações do NRC (Nutrient...,1996).

A palma forrageira na forma in natura apresenta limitações no teor de proteína bruta e de fibra quando utilizada como principal ingrediente nas dietas de vacas em lactação, apresentando baixo desempenho, distúrbios metabólicos, especialmente diarréias e diminuição no teor de gordura do leite (Santos et al., 1992; Perazzo Neto, 1999; Araújo, 2004). Portanto, para suprir tais deficiências, utilizou-se a levedura Saccharomyces cerevisiae no seu enriquecimento protéico e obteve-se, além do aumento de proteína bruta, acréscimo no teor de FDN do bioproduto, conforme o NRC (Nutrient..., 1996).
Pela Tab. 3, observa-se que não houve diferença entre os teores de MS da palma forrageira enriquecida com 1, 2 e $3 \%$ de levedura, estando abaixo do limite máximo preconizado pelo NRC (Nutrient..., 1996), que é de 50\%, abaixo do qual o consumo será limitado. Isso significa que a palma forrageira somente deve ser utilizada na dieta dos animais complementada com uma fonte de fibras que garanta, principalmente, maiores concentrações dos teores de MS para suprir as necessidades desse nutriente (Santos et al., 1992; Oliveira, 1996).

Perazzo Neto (1999), ao utilizar o microrganismo Aspergillus niger no enriquecimento protéico da palma forrageira, obteve maior concentração do teor de matéria seca de aproximadamente $9 \%$ em relação ao valor encontrado na forma in natura correspondente a $8 \%$.

Os efeitos concentração do inóculo e tempo de fermentação sobre os teores de proteína bruta foram maximizados em $2 \%$ e 12 horas, e não apresentaram diferença estatística em relação ao tempo de inoculação. Observa-se na Tab. 3 que as variáveis: concentração de inóculo e tempo de inoculação não apresentam efeitos significativos de interação.

Araújo (2004), ao estudar o enriquecimento protéico da palma forrageira, verificou que o tempo ótimo para alcançar o maior valor de proteína bruta no substrato enriquecido foi de 48 horas do processo. Nas concentrações de 5, 10 e $15 \%$ de levedura Saccharomyces cerevisiae obteve valores maximizados de proteína bruta de $14,4,22$ e $26 \%$, respectivamente. 
Tabela 3. Teores médios dos nutrientes da composição química da palma forrageira enriquecida com a levedura Saccharomyces cerevisiae, segundo as concentrações do inóculo e tempo de inoculação

\begin{tabular}{lccccccc} 
Fatores & MS & PB & MM & MO & FDN & FDA & EB \\
\hline Concentração de levedura & & & & & & & \\
$1 \%$ & $7,44 \mathrm{a}$ & $7,90 \mathrm{~b}$ & $15,49 \mathrm{a}$ & $84,51 \mathrm{a}$ & $53,18 \mathrm{a}$ & $25,37 \mathrm{ab}$ & $3.921 \mathrm{a}$ \\
$2 \%$ & $7,56 \mathrm{a}$ & $9,75 \mathrm{a}$ & $15,52 \mathrm{a}$ & $84,48 \mathrm{a}$ & $51,85 \mathrm{ab}$ & $26,99 \mathrm{a}$ & $3.941 \mathrm{a}$ \\
$3 \%$ & $7,50 \mathrm{a}$ & $9,17 \mathrm{a}$ & $15,56 \mathrm{a}$ & $84,41 \mathrm{a}$ & $48,47 \mathrm{~b}$ & $27,73 \mathrm{~b}$ & $3.899 \mathrm{a}$ \\
Tempo de inoculação & & & & & & & \\
6 & $7,36 \mathrm{a}$ & $8,72 \mathrm{a}$ & $15,41 \mathrm{a}$ & $84,59 \mathrm{a}$ & $50,98 \mathrm{a}$ & $24,85 \mathrm{a}$ & $3.963 \mathrm{ab}$ \\
12 & $7,48 \mathrm{a}$ & $9,41 \mathrm{a}$ & $15,51 \mathrm{a}$ & $84,45 \mathrm{a}$ & $52,01 \mathrm{a}$ & $24,97 \mathrm{a}$ & $3.801 \mathrm{~b}$ \\
24 & $7,66 \mathrm{a}$ & $8,72 \mathrm{a}$ & $15,44 \mathrm{a}$ & $84,56 \mathrm{a}$ & $51,99 \mathrm{a}$ & $25,69 \mathrm{a}$ & $3,926 \mathrm{ab}$ \\
36 & $7,50 \mathrm{a}$ & $8,9 \mathrm{a}$ & $15,7 \mathrm{a}$ & $84,27 \mathrm{a}$ & $49,68 \mathrm{a}$ & $25,95 \mathrm{a}$ & $3.992 \mathrm{a}$ \\
\hline
\end{tabular}

Médias seguidas por letras distintas na coluna diferem entre si, pelo teste Tukey $(\mathrm{P}<0,05)$.

Não houve efeito significativo da interação concentração de levedura x tempo de inoculação.

Em relação à MM, observa-se que houve um aumento de mais de três vezes do teor deste nutriente na palma enriquecida quando comparado com a palma forrageira na forma in natura $(4,38 \%)$.

Quanto aos teores de FDN e FDA, houve uma variação de 48,5 a $53,2 \%$ e de 25,4 a $26,9 \%$, respectivamente. As recomendações mínimas do NRC (Nutrient..., 1996) são de $28 \%$ para FDN e $21 \%$ para FDA. Os resultados obtidos assemelharam-se aos de Oliveira (1996), isto é, ao oferecer palma forrageira aos animais, devese associá-la com alimentos ricos em proteínas para suprir a deficiência desse nutriente e de fibras, para estimular a produção de saliva e manutenção das condições normais do rúmen.

Não foram detectadas diferenças significativas $(\mathrm{P}>0,05)$ entre os teores de energia bruta da palma forrageira nas concentrações de inóculos estudadas. Apesar de a levedura utilizar os carboidratos para síntese de proteínas, não houve redução no valor energético do bioproduto.

O valor maximizado para EB foi de $3991 \mathrm{kcal} / \mathrm{g}$, equivalente ao aumento de $2 \%$ em relação ao teor de EB da palma forrageira in natura. Esse aumento significa que a palma possui carboidratos, principalmente monossacarídeos, na sua composição química, que podem ser utilizados pelas leveduras no processo de fermentação, além de ser considerada uma das principais fontes de calor e energia.

A bioconversão da palma forrageira em bioproduto de alto valor agregado similar ou maior que alguns concentrados convencionais pode ser utilizada como alternativa alimentar, nos sistemas de produção animal do semi-árido nordestino do Brasil.

\section{REFERÊNCIAS BIBLIOGRÁFICAS}

ARAÚJO, L.F. Enriquecimento protéico do mandacaru sem espinhos Cereus jamacaru (P.DC) e palma forrageira (Opuntia ficus-indica Mill) por fermentação semi-sólida. 2004. 195f. Tese (Doutorado)-Universidade Federal de Campina Grande, Campina Grande, PB.

ARAÚJO, L.F.; MEDEIROS, A.N.; PERAZZO NETO, A. et al. Protein Enrichment of Cactus Pear (Opuntia ficus-indica Mill) using Saccharomyces cerevisiae in solid-state fermentation. Bras. Arch. Biol. Tecnol., v.8, p.161-168, 2005.

BUTOLO, J.E. Leveduras vivas e termolizadas na alimentação animal. In: SIMPÓSIO SOBRE INGREDIENTES ALTERNATIVOS NA ALIMENTAÇÃO ANIMAL, 2001, Campinas. Anais... Campinas: Colégio Brasileiro de Nutrição Animal, 2001. p.191-198.

CAMPOS, A.R.N.; SANTANA, R.A.C.; DANTAS, J.P. et al. Enriquecimento protéico do bagaço do pedúnculo de caju por cultivo semisólido. Rev. Biol. Cienc. Terra, v.5, p.1-11, 2005.

CARVALHO, M.A.H. Influência do cultivo dos fungos Aspergillus niger e Fusarium oxysporum sobre a composição química da palma forrageira (Opuntia ficus-indica Mill). 1999. 38f. Dissertação (Mestrado) - Universidade Federal da Paraíba, Areia, PB. 
CORREIA, R.; MAGALHÃES, M.; MACEDO G. Protein enrichment of pineapple waste with Saccharomyces cerevisiae by solid state bioprocessing. J. Sci. Ind. Res., v.66, p.259-262, 2007.

FRAZIER, W.C.; WESTHOFF, D.C. (Eds). Microbiologia de los alimentos. 4.ed. Zaragoza: Acribia, 1993. 618p.

HOLANDA, J.S.; OLIVEIRA, A.J.; FERREIRA, A.C. Enriquecimento protéico de pedúnculos de caju com emprego de leveduras, para alimentação animal. Pesq. Agropec. Bras., v.33, p.787-792, 1998.

NUTRIENT requeriments of beef cattle. 7.ed. Washington: National Academy of Sciences, 1996. 242p.

OFFICIAL analytical chemists. 15.ed. Washington: AOAC, 1990. 875p.

OLIVEIRA, F.R. Alternativas de alimentação para pecuária no semi-árido nordestino. In: SIMPÓSIO NORDESTINO DE RUMINANTES, 6., 1996, Natal. Anais... Natal: UFRN, 1996. p.127-147.

PEPPLER, H.J. Food yeasts. In: ROSE, A.H.; HARRISON, J.S. (Eds). The Yeast: Yeast tecnology. London: Academic Press, 1970. p.421-462.

PERAZZO NETO, A. Determinação de parâmetros para o enriquecimento protéico da algaroba (Prosopis juliflora) com Aspergillus niger. 1999. 130f. Tese (Doutorado) Universidade Federal do Rio de Janeiro, Rio de Janeiro, RJ.

PIMENTEL, P.G.; MOURA, A.A.A.N.; NEIVA, J.N.M. et al. Consumo produção de leite e estresse térmico em vacas da raça Pardo-Suiça alimentadas com castanha de caju. Arq. Bras. Med. Vet. Zootec., v.59, p.1523-1530, 2007.

SANTOS, M.V.E.; LIRA. M.A.; FARIAS, I. et al. Efeito do armazenamento pós-colheita sobre o teor de matéria seca e composição química das palmas forrageiras. Pesq. Agropec. Bras., v.27, p.777-783, 1992.

SILVA, J.D. Análise de alimentos. Métodos químicos e biológicos. Viçosa: UFV, 1998. 168p.

USER'S guide: Statistics. Version 6, 4.ed. Cary, NC: SAS Institute, 1990.

VILAS BOAS, S.G.; ESPOSITO, E. Bioconversão do bagaço de maçã: Enriquecimento nutricional utilizando fungos para produção de um alimento alternativo de alto valor agregado. Rev. Biotec., v.3, p.38-42, 2000.

WORGAN, J.T. Protein production by microorganisms from carbohydrate substrates, In: JONES, J.G.W. (Ed). The biological efficiency of protein production. Cambridge: University Press, 1973. p.339-371. 